\title{
Educación Religiosa en Costa Rica: confesionalidad, neutralidad, interculturalidad
}

Religious Education in Costa

Rica: Confessionality, Neutrality, Interculturality

Educação Religiosa em Costa Rica: confessionalidade, neutralidade, interculturalidade

José Mario Méndez Méndez jmariomendez@gmail.com Recibido: 9 de febrero de 2015 Aprobado: 24 de marzo de 2015

\section{Resumen}

El autor propone aquí un modelo de educación religiosa que recoge el pronunciamiento de la Sala de lo Constitucional, así como los desafíos del contexto cada vez más mutirreligioso de Costa Rica. Se trata de una propuesta que va más allá de lo ecuménico y de lo interrreligioso y, que tiene como finalidad, generar procesos educativos inclusivos, orientados a educar desde la convivencia en la diversidad y capaces de hacer de la diversidad de creencias, espiritualidades y convicciones, una ocasión para aprender.

Palabras clave: educación religiosa, interculturalidad, religión, espiritualidad

\begin{abstract}
The author proposes here a model of religious education that includes the pronouncement of the Constitutional Chamber and the challenges of increasingly mutireligious context of Costa Rica. It is a proposal that goes beyond the ecumenical and the inter-religious issue and that aims to generate inclusive educational processes oriented toward educating
\end{abstract}


from coexistence in diversity and capable of making the diversity of beliefs, spirituality and convictions a chance to learn.

Keywords: religious education, interculturality, religion, spirituality

\section{Resumo}

$\mathrm{O}$ autor propõe aqui um modelo de educação religiosa que contempla o pronunciamento da Sala Constitucional, assim como os desafios do contexto cada vez mais multirreligioso de
Costa Rica. Trata-se de uma proposta que vai mais além do ecumênico e do inter-religioso, e que tem com finalidade gerar processos educativos inclusivos, orientados a educar a partir da convivência na diversidade e capazes de fazer da diversidade de crenças, espiritualidades e convicções, uma ocasião para aprender.

Palavras chave: educação religiosa, interculturalidade, religião, espiritualidade

\section{Introducción}

En la cosmología de los pueblos Bribrí y Cabécar, las mujeres y los hombres fuimos creados por Sibö a partir de semillas de maíz. Los diversos colores del maíz con que fuimos creados determinan la pertenencia a los distintos clanes o razas. Para estos pueblos originarios de Costa Rica, somos diferentes desde el acto creador:

Trajo las semillas de un lugar que se llama SuLa'kaska (lugar de Destino). De ahí Sibö trajo semillas de distintos colores, como maíz negro, maíz blanco, amarillo y morado. Por esta razón algunos de los indios somos negros de color, otros son casi blancos, otros amarillos... ${ }^{1}$

La diversidad es, para estos pueblos, una condición humana, una forma de vivir (con-viviendo). Ella desborda a las personas y se extiende a todos los seres que cohabitan el mundo: plantas, animales, paisajes.

1 Juan Vargas, "Orígenes del indígena," en Vías de extinción. Vías de supervivencia: testimonios del pueblo indígena de la reserva Kéköldi, Costa Rica, coords. Paula Palmer et al. (San José: Ed. Legado, 1992): 36. 
La diversidad de espiritualidades, creencias, convicciones y adhesiones a grupos y movimientos religiosos, es parte de la condición humana de quienes habitamos hoy este continente tan plural, y coincide con su maravillosa biodiversidad.

Nuestra diversidad se convierte en potenciadora de la convivencia cotidiana. En los ambientes educativos, la diversidad propicia aprender con-viviendo, a pesar de que no falta quienes la ven como una dificultad o un problema por resolver. En efecto, la existencia de una cultura dominante y de religiones oficiales o hegemónicas, dificulta el desarrollo de procesos educativos inclusivos, interculturales y en diálogo con los contextos.

El reconocimiento de la diversidad religiosa de Costa Rica es el primer paso hacia la revisión de la educación religiosa que se promueve en las instituciones educativas y para la renovación de las prácticas pedagógicas en esa área del saber. Todo esfuerzo de revisión y transformación de la educación religiosa en Costa Rica debe estar orientado a la superación definitiva del modelo confesional, y a la construcción de procesos educativos que fortalezcan el aprendizaje y la convivencia desde la experiencia de la diversidad. De esta manera, independientemente del color del maíz con que fuimos constituidos, entenderemos la educación como una ocasión para aprender a partir de la diversidad, no a pesar de ella.

\section{Modelos de educación religiosa}

Se entiende por modelo de educación religiosa la forma envolvente de comprender, organizar y accionar, en un determinado contexto y momento histórico, prácticas educativas en el ámbito de la educación religiosa. Lo envolvente es la cualidad por la que un determinado modelo traspasa diversos elementos del proceso educativo: la formación docente, el planeamiento, los recursos didácticos, las situaciones de aprendizaje, las estrategias 
de evaluación, la interacción entre las personas aprendientes, entre otros. La diversidad de modelos muestra la pluralidad de enfoques epistemológicos que pueden concurrir y co-existir en las experiencias educativas.

Hay que aclarar que, en las prácticas educativas concretas, lo que encontramos es la combinación de dos o más modelos, con alguna acentuación particular. La acentuación está condicionada, entre otras cosas, por el grado de intervención de las iglesias y los movimientos religiosos en los procesos educativos, por las políticas educativas, por el tipo de formación que han recibido las personas educadoras, así como por la capacidad para dar respuesta a las demandas del entorno, por la existencia o no de concordatos y de otro tipo de acuerdos con el Vaticano, entre otros.

La diversidad de modelos que aparece en las referencias bibliográficas es sobre la educación religiosa escolar. Por ejemplo, João Décio Passos, distingue tres modelos de educación religiosa en Brasil: el modelo catequístico (claramente confesional); el modelo teológico (más ecuménico que el primero); y el modelo que denomina "de las ciencias de la religión" (que pretende establecer la autonomía epistemológica de la educación religiosa)².

Gabriel Alfonso Suárez y sus colegas investigadores proponen, desde Colombia, el modelo que denominan "educación escolar liberadora" como alternativa a los modelos de clase de religión o a aquellos que dan primacía a la ilustración religiosa o que han sustituido la formación religiosa por asuntos propios de la ética, la axiología y la ciudadanía ${ }^{3}$.

2 Cfr. João Décio Passos. Ensino Religioso. Construção de uma proposta (São Paulo: Ed. Paulinas., 2007), 50-68.

3 Cfr. Grabriel Alfonso Suárez et al., "Educación religiosa escolar en clave liberadora: elementos constitutivos," en Theologica Xaveriana, vol. 63/1, núm. 175 (enero-junio 2013): 221-222. 
Para el caso boliviano, Matthias Preiswerk distingue tres modelos que corresponden a tres momentos de la historia del país: antes de la reforma liberal (clase de religión); durante la reforma liberal (educación en valores o bien ética y moral); y el actual período, que corresponde al Estado plurinacional (que acentúa el conocimiento de las tradiciones religiosas ancestrales). ${ }^{4}$

Se presentará a continuación un resumen de algunos de los modelos que, con distintos nombres, son descritos por esos y otros estudiosos de la educación religiosa. En cada modelo me referiré al menos a los siguientes elementos: los presupuestos de los que se parte, los objetivos que se pretenden alcanzar, el objeto de estudio, y la forma en que se comprende a los docentes y estudiantes y, a las interacciones de ambos.

\section{Modelo de enseñanza de la religión}

El primer modelo, al que denomino "enseñanza de la religión", tiene como presupuesto precisamente la convicción de que la religión puede ser enseñada. Presupone, también, que los estudiantes pertenecen o deberían pertenecer a una comunidad eclesial o religiosa. La educación religiosa se comprende, por eso, como actividad pastoral o evangelizadora.

Desde este modelo se busca educar desde y hacia la fe religiosa, así como ofrecer una educación religiosa y moral que corresponda a las convicciones y creencias de los padres, madres o personas tutores. El objeto de estudio es la doctrina de la Iglesia.

Este es el modelo que está presente, por ejemplo, en la propuesta de educación religiosa escolar de la Conferencia Episcopal de Costa Rica, cuya finalidad última es inculturar el evangelio: "La

4 Cfr. Matthias Preiswerk. "Las aulas: espacio de conflicto entre laicidad, confesionalidad e indigenización," en Tinkazos v.16, n.33 (junio 2013): 161-175. Ver también, de este mismo autor, "Educación religiosa en la escuela: de confesional a interreligiosa," en Revista Fe y Pueblo de Dios (junio 2009): 4-35. 
educación religiosa escolar será también inculturación de la fe en el sentido de encarnar el Evangelio en el área cultural escolar, con una fuerza crítica y generadora, a la vez, de nueva cultura religiosa"s.

Según los obispos, la educación religiosa es una concesión del Estado Costarricense a la Iglesia Católica. Esta última determina el enfoque, contenidos y propósitos: "Por consiguiente, es clara la intencionalidad del Estado sobre la confesionalidad católica de la Educación Religiosa Escolar"6. Por eso, precisamente, la educación religiosa no puede estar separada de la misión de la Iglesia.

También podemos reconocer este modelo en la educación religiosa que la Sala Constitucional, si se toman en cuenta la diversidad de creencias, solicita al Ministerio de Educación, para una primera etapa del sistema educativo costarricense. En esta etapa se pide que "los estudiantes que profesan un credo religioso diverso al católico -debidamente reconocido y aceptado por el Estado-, puedan recibir lecciones de una persona que tenga idoneidad comprobada para impartirla" . Las personas educadoras, según esta solicitud de la Sala Constitucional, deberán ser elegidos entre las personas más idóneas para impartir un tipo de enseñanza religiosa enfocada en un credo determinado, según la demanda del estudiantado.

En este modelo, que es el que ha predominado hasta ahora, la persona educadora es entendida como misionera, evangelizadora, conocedora de la doctrina que debe enseñar. La educación religiosa exige la confesionalidad del docente ${ }^{8}$.

5 Conferencia Episcopal de Costa Rica. Educación. Iglesia y sociedad para el desarrollo humano y social en el inicio del nuevo milenio (San José: CECOR, 2002), 73-74.

6 Conferencia Episcopal de Costa Rica, Iglesia y sociedad..., 74.

7 Sala de lo Constitucional. Resolución 2030-2010, N IX.

8 Cfr. Sala Constitucional, ... 77. 


\section{Modelo ecuménico ecléctico}

Este segundo modelo tiene como presupuesto la convicción de que el estudiantado forma parte de alguna iglesia o grupo religioso, y que es posible convivir si se respeta a quienes creen diversamente. Busca educar en el respeto hacia las distintas creencias religiosas de las personas que participan en el proceso educativo.

El objeto de estudio está constituido por las experiencias religiosas diversas y los aportes de las distintas tradiciones religiosas (sobre todo cristianas), que reconocemos en la sociedad costarricense.

Las personas educadoras deben contar con habilidades para acompañar procesos educativos en los que confluyan los saberes y experiencias religiosas de las personas que participan en el proceso educativo, para promover la convivencia y el respeto a la diversidad. Los estudiantes son personas en formación que pertenecen a distintas iglesias, movimientos religiosos y a quienes se les invita a cultivar actitudes de respeto y reconocimiento de la diversidad.

Este segundo modelo podemos reconocerlo, por ejemplo, en la propuesta de educación religiosa de la Sala Constitucional, para lo que los jueces denominan "segunda etapa". En esta etapa, la educación religiosa debería asumir "un enfoque ecuménico o ecléctico que fomente la tolerancia, el respeto de los derechos humanos y fundamentales de la dignidad humana, la diversidad religiosa, la no discriminación por razones religiosas, el entendimiento, la comprensión y la amistad entre los grupos religiosos"

\section{Modelo de "cultura religiosa"}

Este tercer modelo tiene como punto de partida la convicción de que, para aprender a vivir y convivir en un

9 Sala Constitucional. Resolución 2030-2010, Nº IX. 
contexto multirreligioso como el nuestro, el estudiantado necesita conocer mejor las distintas tradiciones religiosas y sus aportes a la humanidad.

Lo que se busca es, fundamentalmente, desarrollar el conocimiento sobre las manifestaciones religiosas, entendidas como producciones culturales, así como fomentar actitudes de respeto y tolerancia hacia las mismas. El objeto de estudio es lo religioso, en sentido genérico, como elemento presente en todas las culturas. Según este modelo es posible realizar un estudio comparado de las religiones para conocer sus aportes, sus elementos comunes y sus diferencias.

Al gremio de educadores se les solicita conocer las distintas tradiciones religiosas, sus orígenes, su historia y sus aportes.

Este es el modelo de educación religiosa que se ha privilegiado en los países europeos de tradición cristiana en los que crece la migración de personas con tradiciones religiosas distintas.

\section{Modelo de educación en valores}

Este modelo, a veces también denominado educación ética, ha sido promovido en aquellos lugares en los que se sospecha que la educación religiosa es necesariamente confesional y que, por eso mismo, no es tarea de las escuelas y colegios. Su lugar está exclusivamente en las iglesias y las familias.

Se trata, entonces, de sustituir la educación religiosa por experiencias educativas seculares, que acentúan lo ético y lo axiológico.

El punto de partida de este modelo es la posibilidad de educar en una serie de valores predefinidos. La convivencia y la ciudadanía exigen asumir y vivir esos valores, sobre todo en tiempos caracterizados por una supuesta crisis de valores. 
El objetivo, en este modelo, es fomentar el respeto mutuo, así como actitudes coherentes con una ética ciudadana. El objeto de estudio está formado por los valores y las normas de convivencia establecidas en una determinada sociedad.

El educador debe desarrollar las competencias y habilidades para educar en valores éticos y ciudadanos. El estudiantado es integrante de una comunidad (familiar, civil, nacional...) que debe apropiarse de ciertos valores para poder convivir adecuadamente en una época de crisis.

Hay que advertir que, también, desde la educación en valores, se corre el riesgo de promover procesos educativos fundamentalistas, homogenizantes y moralizantes. En este sentido, vale la pena preguntarse: ¿quién establece, y por qué, los valores que se enseñan?, ¿quién determina el significado de cada valor?

\section{Modelo de inclusión de tradiciones ancestrales}

Este modelo es el que podemos reconocer, por ejemplo, en la propuesta del Ministerio de Educación del Estado Plurinacional de Bolivia, cuando formula el siguiente objetivo:

Desarrollamos valores éticos, morales y espirituales de las naciones indígena originario campesinas, afro-boliviana y comunidades interculturales a partir de las manifestaciones de espiritualidad, religiosidad y la historia de las religiones, mediante la investigación y el análisis crítico, respetuoso y armónico de la diversidad existente para el ejercicio pleno de la libertad de conciencia y de fe sin imposición dogmática ${ }^{10}$.

En este modelo, que todavía está en construcción, el objeto de estudio está constituido por todas las formas de expresión espirituales y religiosas: "Se considera el tratamiento de las

10 Ministerio de Educación Pública, "Nivel de educación primaria comunitaria vocacional. Programa de estudio.Primer año,"http://www.minedu.gob.bo/phocadownload/curricula/planes\%20programas\%20primaria.pdf (consultado el 22 de agosto de 2014). 
diferentes manifestaciones espirituales y religiosas a partir de los enfoques antropológico, sociológico y de la historia de las religiones, tomando en cuenta la diversidad del Estado Plurinacional boliviano y de la humanidad en su conjunto" ${ }^{11}$.

El gremio de educadores debe conocer las diversas tradiciones religiosas, especialmente aquellas vinculadas a las culturas ancestrales, que se habilitan para analizarlas críticamente. Promueven procesos educativos caracterizados por el respeto y la libertad, consideran la diversidad de creencias que es posible encontrar entre las personas aprendientes.

El estudiantado posee una dimensión espiritual trascendente, pues toda persona es un "ser conectado como parte del todo; esa relación se manifiesta en mitos, rituales, música, danza, literatura y otros, expresadas de diferentes formas en todas las culturas"12.

Este modelo tiene como presupuesto la diversidad de cosmovisiones presentes en el contexto en que se educa, pero entiende que, en ese contexto, existe una cultura dominante y una religión hegemónica, así como unas culturas que han sido marginadas y que son portadoras de tradiciones religiosas invisibilizadas y deslegitimadas.

\section{Educación religiosa: cambios y cuestionamientos}

Aunque circulan diferentes visiones sobre la educación religiosa, generalmente ha prevalecido aquella que comprende los procesos educativos como parte de la pastoral educativa, de la misión evangelizadora de la Iglesia y de los esfuerzos eclesiales por la inculturación del evangelio, es decir, el modelo catequístico o de enseñanza de la religión. Desde esta prevalencia, se concibe a los educadores como misioneros, evangelizadores y

11 Ministerio de Educación Pública, Nivel de educación primaria..., 12.

12 Ministerio de Educación Pública, Nivel de educación primaria..., 12. 
agentes de pastoral y, a las personas estudiantes, como destinatarias de la evangelización, que tienen o deberían tener una adhesión eclesial o religiosa ${ }^{13}$.

Independientemente del modelo que se acentúe en América Latina, la educación religiosa experimenta cambios profundos por diversas razones:

- Los frecuentes cuestionamientos que enfrenta la educación religiosa en los países en que todavía existe. Los cuestionamientos tienen que ver, en la mayoría de los casos, con el carácter fundamentalista, moralizante y homogenizante, que caracteriza a la mayoría de experiencias de educación religiosa desarrolladas en el contexto de la escuela pública.

- La creciente conciencia, por parte de la ciudadanía, acerca del pluralismo cultural y religioso de nuestros países. Cada vez, estamos más y mejor habilitados para reconocer y valorar la diversidad cultural y religiosa de nuestras regiones. Las luchas emprendidas por los grupos históricamente excluidos e invisibilizados de la sociedad, los ha ayudado a ser reconocidos y a recuperar la voz. Se supera, así, un largo período en el que la diversidad (cultural, religiosa, étnica, de orientación sexual, entre otras), fue vista como una amenaza que debía ser superada con prácticas pastorales y educativas, homogenizantes y correctoras. Desde la religión hegemónica, y a veces también oficial, lo diverso tiene rasgos de falsedad y de error, era observado como objeto de condena y rectificación.

13 Ver Conferencia Episcopal de Costa Rica. Educación. Iglesia y sociedad para el desarrollo humano y social en el inicio del nuevo milenio (San José: CECOR, 2002). En el Mensaje a los padres y madres de familia en ocasión del inicio del curso lectivo 2014, el Arzobispo de San José describe la educación religiosa en la escuela pública no sólo como una concesión del Estado a la Iglesia, sino también como un deber del primero, a cargo de laicos comprometidos y orientado a fortalecer la fe del estudiantado. 
- Los cambios relacionados con la educación religiosa en América Latina, también, están motivados por la necesidad de consolidar la separación Iglesia-Estado y de evitar que las instituciones o grupos religiosos impongan puntos de vista acerca de asuntos que afectan a toda la ciudadanía. La histórica alianza Iglesia-Estado que tiene peso en las políticas públicas de muchos países, y se expresa en modalidades diversas como la religión oficial, el concordato, los acuerdos o, simplemente, no tiene figura legal, sino que existe como poder religioso que atraviesa todo el entramado social. Frente a ese poder religioso, y sobre todo frente a los abusos de ese poder, es que se reacciona hoy; por eso se desconfía de proyectos educativos por los que transitan las propuestas éticas y las perspectivas antropológicas y sociales de los grupos religiosos.

En el caso de Costa Rica, la educación religiosa se fundamenta en la Ley $\mathrm{N}^{\circ} 21$ del 10 de noviembre de 1940, que estipula lo siguiente: "Establézcase en las escuelas primarias del Estado la enseñanza de la religión, que se dará a los niños cuyos padres, tutores o encargados, no manifiesten por escrito su voluntad de que se les exima de recibirla".

Además, en el decreto $\mathrm{N}^{\circ}$ 3, del 6 de abril de 1963, se establece la materia de Religión (optativa para los no católicos) en la educación media costarricense ${ }^{14}$.

En el pasado reciente, fue fuertemente cuestionado el artículo de la Ley de la Carrera Docente, según el cual la Missio Canónica (autorización que otorga la Conferencia Episcopal Nacional), era considerada requisito para la selección del personal dedicado a la enseñanza de la religión en los centros educativos públicos.

14 Curiosamente, sólo dos años después, en el Reglamento General Establecimientos Oficiales de Educación Media (decreto ejecutivo $\mathrm{N}^{\circ} 2$ del 3 de marzo de 1965), se prohibía al profesorado, entre otras cosas, "Dirigir ataques contra las creencias religiosas de los alumnos o de las familias de éstos”. 
El cumplimiento de esa normativa hizo que fueran excluidas del ejercicio de la docencia todas las personas a quienes, por diversas razones, la Conferencia Episcopal negaba la Missio Canónica. Esta no era otorgada, por ejemplo, a personas no católicas, y casi siempre era negada a quienes no habían estudiado en la Universidad Católica.

Esta normativa fue declarada inconstitucional en el año $2010^{15}$. A partir de entonces, la educación religiosa en la escuela pública debe desarrollarse y transformarse sin el condicionamiento de iglesias o grupos religiosos.

La resolución de la Sala Constitucional fundamenta su decisión en el principio de neutralidad religiosa del Estado Costarricense en materia educativa. La confesionalidad actual del Estado (Art. 75 de la Constitución Política), no afecta ese principio de neutralidad religiosa:

A partir de la regulación separada de la religión y la educación en la norma fundamental, resulta factible inducir el principio de la neutralidad religiosa del Estado en el ámbito educativo, de acuerdo con el cual los poderes públicos deben asumir una posición aconfesional en el terreno educativo para promover y fomentar la diversidad y libertad religiosa ${ }^{16}$.

Como consecuencia del voto de la Sala de lo Constitucional, el Ministerio de Educación Pública está en la obligación de diseñar propuestas educativas novedosas, inclusivas, que rompan con

15 La parte dispositiva de la sentencia de la Sala Constitucional indica: Se declara con lugar la acción y en consecuencia se anula el Art. 34 párrafo segundo del Reglamento a la Ley de la Carrera Docente (Decreto ejecutivo número 2235-E-P del 14 de febrero de 1972) que dice lo siguiente: "Para la selección del personal dedicado a la educación religiosa, será requisito indispensable la autorización previa que extenderá la Conferencia Episcopal Nacional. Sin embargo, la elaboración de las bases y promedios ponderados para la selección previa, tanto del personal propiamente docente como del personal técnico y administrativo docente, estará cargo de Jurados Asesores de la Dirección General.

16 Sala Constitucional. Resolución 2030-2010, N VI. 
el modelo de educación religiosa que ha prevalecido, que no riñan con el principio de neutralidad religiosa del Estado en materia educativa y que acojan la diversidad cultural y religiosa del país.

Las nuevas propuestas, por lo tanto, deben ser elaboradas desde un enfoque intercultural que favorezca el desarrollo de procesos educativos inclusivos y respetuosos de las creencias, las no creencias, las convicciones y las espiritualidades de todas las personas.

\section{Hacia un nuevo modelo: transformación intercultural de la educación religiosa}

Se sugiere, a continuación, un nuevo modelo de educación religiosa que recoja tanto el espíritu del pronunciamiento de la Sala de lo Constitucional, como los desafíos del contexto cada vez más multi-religioso de Costa Rica. Se trata de una propuesta que va más allá de lo neutral, de lo ecuménico y de lo interrreligioso y, que tiene como finalidad, generar procesos educativos inclusivos, orientados a educar desde la convivencia en la diversidad y capaces de hacer de la diversidad de creencias, espiritualidades y convicciones, una ocasión para aprender ${ }^{17}$.

\section{a. De la neutralidad a la interculturalidad}

La neutralidad parece ser una categoría pasiva y negativa, pues lleva implícita la ausencia de posicionamiento, el no involucramiento, la imparcialidad. Sin embargo, ella abre posibilidades inéditas en la educación religiosa costarricense: por una

17 Podemos reconocer esos rasgos, por ejemplo, en los trabajos realizados en Brasil, especialmente en el Estado de Santa Catarina. Por ejemplo: Lilian Blanck et al., Ensino Religioso: no ensino fundamental (São Paulo: Cortez, 2007); Forum Nacional Permanente de Ensino Religioso. Caderno Temático 2. Culturas e Tradições Religiosas (Curitiba: FONAPER, 2001); Elcio Cecchetti, "Diversidade religiosa e currículo escolar: presenças, ausências e desafíos" (conferencia presentada em el IX ANPED SUL, Seminario de pesquisa em educação, Universidad de Caxias do Sul, 29 de julio al 1 de agosto, 2012; Adecir Prozzer et al., Diversidade Religiosa e Ensino Religioso no Brasil: Memórias, Propostas e Desafios (São Leopoldo: Nova Harmonia, 2010). 
parte, asegura que ninguna iglesia volverá a imponer criterios en el currículo educativo, ni volverá a interferir en la selección del personal docente; por otra parte, sugiere la posibilidad de generar propuestas educativas en las que confluyan todas las creencias y no creencias, todas las adhesiones eclesiales, todas las convicciones, tradiciones y experiencias religiosas del contexto en que vivimos, con-vivimos y educamos.

Es necesario aclarar que la neutralidad religiosa a la que nos referimos, no significa neutralidad pedagógica y social, ni implica que las personas aprendientes (docentes y estudiantes), tengan que poner entre paréntesis (o renunciar a) sus convicciones, creencias o adhesiones religiosas. Por el contrario, la educación religiosa implica una parcialidad pedagógica y social: la parcialidad que nos pone del lado de la inclusión y en contra de prácticas educativas discriminatorias, e implica tener como punto de partida, precisamente, el reconocimiento del derecho que todas las personas tienen a buscar y construir fundamentación para la vida y la convivencia.

El principio de neutralidad obliga al Estado a impedir toda forma de confesionalidad en la educación y todo intento de control de la educación religiosa por parte de una determinada iglesia o grupo religioso; tal principio obliga al mismo Estado a promover procesos educativos en los que nadie se vea excluido o marginado por causa de su adhesión o no adhesión a una iglesia, o por sus convicciones, creencias o no creencias.

Dicho de manera más positiva: se trata de generar procesos educativos interculturales en los que todos se sientan en casa, a gusto, con deseos de aprender, a partir de la con-fluencia y la con-vivencia en la diversidad.

Se trata de una educación que va más allá de lo ecuménico (porque no todas las expresiones y adhesiones religiosas se dan en 
el marco de las tradiciones cristianas), y más allá de lo interreligioso (pues muchas creencias, convicciones y espiritualidades no llegan a poseer institucionalidad religiosa y muchas personas deciden realizar sus búsquedas de sentido y de fundamentación al margen de las religiones). La educación religiosa debería incluir, entonces, todas las re-ligaciones ${ }^{18}$ que nos vinculan a otras personas, a la naturaleza, al cosmos y que son fuente de sentido, de fundamentación para la vida.

Aquí vale la pena recordar que el concepto religión está fuertemente limitado por su carácter eurocéntrico. Por eso, desde la educación religiosa se puede correr el riesgo de reducir lo religioso a sus expresiones monoteístas más históricamente reconocidas y, deja de lado, que se trata de una experiencia humana necesariamente plural y contextual ${ }^{19}$. Esa pluralidad es lo que queremos rescatar desde la perspectiva intercultural.

Todas las personas, en todas las culturas, experimentamos necesidad de dar fundamento a lo que hacemos, a lo que dejamos de hacer, a la vida, a la muerte, a las luchas comunitarias, a nuestras relaciones con otras personas y con el mundo, a la historia. Como las culturas son distintas, las fundamentaciones adquieren lenguajes distintos, representaciones simbólicas distintas, prácticas diferentes, discursos diferenciados. La educación religiosa intercultural exige aprender a convivir en esa diversidad, a verla como una posibilidad para el aprendizaje, para la convivencia y para la construcción de relaciones de paz.

18 "Re-ligare" es una de las posibles formas de explicar etimológicamente la categoría religión. Frank Usarski recuerda estas otras: "re-legere" (observación minuciosa y repetición escrupulosa de algo relacionado a los rituales); "re-eligere" (reelección); "relinquere" (dejar, abandonar); "rem ligo" (dedicarse a una tarea no terminada). Cfr. Frank Usarski, "Etimologia do termo Religião e suas funçãoes didáticas," en Diálogo, Revista de ensino religioso, Año XVIII, n 71 (agosto-septiembre 2013): 14-15.

19 João Décio Passos, "O objeto da Ciencia da Religiao como problema," en Diálogo, Revista de ensino religioso, Año XVIII, nº 71 (agosto-septiembre 2013): 20. 


\section{b. Lainterculturalidadcomoalternativaalosfundamentalismos y a los procesos educativos homogenizantes.}

La educación religiosa, como otras áreas del saber, ha quedado atrapada, frecuentemente, en fundamentalismos de tipo pedagógico, epistemológico y religioso.

Raúl Fornet Betancourt es, posiblemente, quien con más claridad ha afirmado la posibilidad de superar la violencia y el fundamentalismo (religioso) desde el paradigma de la interculturalidad:

Pues si es cierto que la perspectiva de la interculturalidad puede ayudar a radicalizar el diálogo entre religiones haciendo ver, por ejemplo, la necesidad de liberar las tradiciones e identidades religiosas de las redes monoculturales en que muchas veces se ven atrapadas, no debe caber duda, por otra parte, que el diálogo interreligioso puede ser a su vez una fuente de orientación importante para el trabajo intercultural de recuperar las memorias liberadoras de la humanidad en toda su pluralidad, sin renunciar, por ello, a un fundamento normativo vinculante ${ }^{20}$.

Por una parte, Fornet Betancourt reconoce la irrenunciable búsqueda de fundamentación propia de la condición humana, pero advierte, por otra parte, la diferencia entre fundamentación y fundamentalismo. Éste último implica desacreditación, desconocimiento, rechazo y otras formas de violencia cultural y religiosa. Una transformación intercultural de la educación religiosa, implica emprender un proceso de discernimiento, cuestionamiento y desmontaje de los fundamentalismos que se encuentran y refuerzan en los ambientes educativos, así como recuperar las plurales memorias liberadoras de los pueblos, las comunidades, las tradiciones espirituales y religiosas.

20 Raúl Fornet Betancourt, "La interculturalidad como alternativa a la violencia," http://red.pucp.edu.pe/ridei/files/2011/08/601.pdf 
Para Raúl Fornet, la interculturalidad "no se despide de ninguna memoria cultural o religiosa, portadora de diversidad, sino que, por el contrario, las cita convocándolas a crecer por la comunión entre todas" ${ }^{21}$.

El fundamentalismo religioso consiste en creer que la propia tradición religiosa es la única fuente de sentido y explicación válida. Se basa en el binomio verdad-falsedad, según el cual quien no está en la verdad, presente en una determinada convicción religiosa, está en el error. La consideración de lo diverso como erróneo desencadena procesos misioneros, pastorales y evangelizadores, orientados a salvar del error a quienes no están en la verdad. La salvación pasa por el abandono del error. La interculturalidad hace ver que el binomio verdad-error es inadecuado, cuando nos referimos a las culturas y las religiones.

Los fundamentalismos pedagógicos y epistemológicos determinan la forma en que comprendemos el aprendizaje y la manera en que acompañamos los procesos educativos. Se expresa, por ejemplo, en prácticas educativas centradas en unos textos (sagrados), autores (sagrados), intervenciones y estrategias que son vistas como correctas. Los fundamentalismos ven con recelo y desconfianza otras formas de acceso al saber, otras formas de interacción entre las personas aprendientes, otras ecologías cognitivas, otras fuentes de conocimiento y otros tipos de relación con el entorno.

La superación del fundamentalismo pedagógico y epistemológico pasa por el reconocimiento de la relación que la escuela construye entre saber y poder; por la autocrítica pedagógica; y por la capacidad para comprender los currículos y los programas como oportunidades para dialogar con el contexto

21 Raúl Fornet Betancourt, Interculturalidad y religión. Para una lectura intercultural de la crisis actual del cristianismo (Quito: Ed. Abya Yala, 2007), 106. 
y para reformular propuestas, y no como camisas de fuerza o como norma que hay que obedecer ${ }^{22}$.

\section{c. Otro modelo de educación religiosa es posible y necesario.}

Lo religioso es una disposición de los seres humanos que, en sus búsquedas de sentido y de identidad, se sienten convocados por, vertidos hacia y re-ligado a los otros, las otras, y lo otro (el cosmos, lo conocido, lo desconocido). Así entendido, lo religioso es una realidad pluriforme, contextual, culturalmente condicionada, dinámica como el ser humano mismo y su contexto.

Las prácticas educativas relacionadas con lo religioso del ser humano pueden ser la ocasión para el encuentro, la convivencia y el aprendizaje a partir, precisamente, de esa diversidad. La convicción de que se puede aprender gracias a la diversidad, y no a pesar de ella, es el punto de partida de un modelo de educación religiosa intercultural.

Desde este modelo, lo que se pretende es robustecer la con-vivencia y superar toda forma de discriminación al promover procesos educativos que tienen como punto de partida la diversidad de re-ligaciones del ser humano. Se trata, entonces, de romper con aquellos tipos de relaciones de poder que encubren y naturalizan estereotipos, discriminaciones y preconceptos, busca reconocer lo religioso en su diversidad en lugar de excluirlo de los ambientes educativos ${ }^{23}$.

El objeto de estudio, en este modelo intercultural, está constituido por las relaciones (re-ligaciones) del ser humano (con el otro y la otra, con el mundo, con lo considerado sagrado), cargadas de significación y apoyo para la convivencia en la vida cotidiana. Es importante conocer los aportes de las religiones,

22 Cfr. Marcos Villela, "Rastros del fundamentalismo pedagógico en la formación de profesores," en Archivos de Ciencias de la Educación Vol. 2, N² 2 (2008): 4.

23 Cfr. Elcio Cecchetti et al., "Diversidade religiosa e dereitos humanos: conhecer, respeitar e conviver," en Diversidade Religiosa e dereitos humanos: conhecer, respeitar e conviver (Bluminau: Edifurb, 2013), 35. 
espiritualidades, cosmovisiones y creencias al enriquecimiento de la convivencia y a la construcción de una cultura de paz. En el caso de la educación religiosa costarricense, es urgente superar la invisibilización a la que han sido sometidas las cosmovisiones de los pueblos originarios y afrodescendientes.

Los profesionales de la educación que entienden lo religioso en sentido amplio, más allá de las religiones, como dimensión humana expresada en tradiciones, representaciones, creencias, prácticas y lenguajes diversos; son capaces de generar procesos educativos inclusivos, en los que quepan todos independientemente de sus creencias y no creencias. Tienen claro que la escuela no es un espacio para enseñar la religión o convicciones de una determinada confesionalidad, sino un lugar de construcción de conocimientos sobre la diversidad cultural religiosa. Junto al estudiantado, reflexionan sobre la diversidad religiosa del entorno, analizan el papel de los movimientos y tradiciones religiosas en la conformación y transformación de las culturas, y rechazan toda forma de discriminación fundada en las creencias ${ }^{24}$.

Los estudiantes son, en este modelo, personas que, desde sus re-ligaciones, creencias y no creencias, construyen significados para la vida cotidiana en un contexto de diversidad cultural y religiosa. Para ellos la diversidad religiosa no es un problema que deben enfrentar o un error que hay que corregir, sino un camino hacia el aprendizaje. Son capaces de interesarse por conocer las distintas expresiones de lo religioso que hay en el entorno, para así asumir una postura crítica frente a todas las formas de discriminación fundadas en las creencias y no creencias. Descubren progresivamente al otro en la diversidad, y lo asumen con una actitud de respeto, justicia y solidaridad ${ }^{25}$.

24 Cfr. Elcio Cecchetti et al., "Diversidade religiosa...", 35.

25 Cfr. Cledes Markus, Culturas y religiões: implicações para o ensino religioso (São Leopoldo: IECLB, 2002), 46-47. 
En síntesis: una educación religiosa intercultural se caracteriza, al menos, por lo siguiente:

Ayudará a reconocer la forma en que los hechos y discursos religiosos, y las diferentes espiritualidades, creencias y convicciones, inciden en la vida de las comunidades y de las personas;

los procesos educativos serán plataforma para la con-vocación, la con-vivencia, el reconocimiento de la diversidad y el compromiso a favor de un mundo más habitable para todos;

renunciará a modelos pedagógicos orientados a exigir que las personas aprendientes repitan y crean lo que alguien, en algún lugar y en algún momento, establece como "verdadero";

habilitará a las personas aprendientes para identificar las invitaciones de las distintas tradiciones religiosas, a la reconciliación, la paz y la justicia entre las personas y con el mundo;

generará procesos educativos no homogenizantes, en los que todas las personas aprendientes, sin renunciar a sus fundamentaciones espirituales, a sus convicciones, creencias o no creencias, se sentirán a gusto, en casa;

contribuirá a comprender la diversidad religiosa y cultural no como una amenaza, sino como oportunidad para la convivencia, el aprendizaje y el compromiso;

ayudará a identificar y superar toda expresión de fundamentalismo y violencia cultural y religiosa;

promoverá desde los ambientes educativos, el diálogo entre religiones, convicciones, creencias y espiritualidades;

valorará la diversidad de formas de acceso al saber presentes en las distintas tradiciones culturales y religiosas. 


\section{Referencias bibliográficas}

Blanck, Lilian. et al. 2007. Ensino Religioso: no ensino fundamental. São Paulo: Cortez.

Cecchetti, Elcio. 2012. Diversidade religiosa e currículo escolar: presenças, ausências e desafíos. Conferencia presentada em el "IX Anped Sul, Seminario de pesquisa em educação", Universidad de Caxias do Sul, 29 de julio al 1 de agosto, consultado en julio 2014 en www.ucs.br/etc/conferencias/ index.php/anpedsul/9anpedsul/paper/viewFile/2968/946

Cecchetti, Elcio, Lilian Blanck, Lúcia Schneider y Simone Riske-Koch,. 2013. "Diversidade religiosa e dereitos humanos: conhecer, respeitar e conviver," en Diversidade Religiosa e dereitos humanos: conhecer, respeitar e conviver, orgs. Reinaldo Matias et al., 1-18. Bluminau: Edifurb.

Conferencia Episcopal de Costa Rica. 2002. Iglesia y Sociedad, de la Conferencia Episcopal Costarricense. San José: CECOR.

Fornet Betancourt, Raúl. 2004. La interculturalidad como alternativa a la violencia. En Filosofar para nuestro tiempo en clave intercultural, 93-104. Aachen: Wissenschaftsverlag Mainz.

2007. Interculturalidad y religión. Para una lectura intercultural de la crisis actual del cristianismo. Quito: Ed. Abya Yala.

Forum Nacional Permanente de ensino religioso. 2001. Caderno Temático 2. Culturas e Tradições Religiosas. Curitiba: FONAPER.

Markus, Cledes. 2002. Culturas y religiões: implicações para o ensino religioso. São Leopoldo: IECLB.

Ministerio de Educación Pública. Nivel de educación primaria comunitaria vocacional. Programa de estudio. Primer año, http://www.minedu.gob.bo/phocadownload/curricula/ 
planes\%20programas\%20primaria.pdf (consultado el 22 de agosto de 2014)

Palmer, Paula et al. 1992. Vias de extinción. Vias de supervivencia: testimonios del pueblo indígena de la reserva Kéköldi, Costa Rica. San José: Ed. Legado.

Passos, Joao Décio. 2013. O objeto da Ciencia da Religiao como problema. Diálogo, Revista de ensino religioso, Año XVIII, $\mathrm{n}^{\circ} 71$ (agosto-setiembre): 20-6.

Preiswerk, Matthias. 2009. Educación religiosa en la escuela: de confesional a interreligiosa. Revista Fe y Pueblo de Dios (junio): 4-34.

2013. Las aulas: espacio de conflicto entre laicidad, confesionalidad e indigenización. Tinkazos v.16 n.33 (junio): $161-75$.

- Prozzer, Adecir, Lilian Blanck, Elcio Cecchetti et al., org., Diversidade Religiosa e Ensino Religioso no Brasil: Memórias, Propostas e Desafios (São Leopoldo: Nova Harmonia, 2010).

Suárez, Grabriel Alfonso et al. 2013. Educación religiosa escolar en clave liberadora: elementos constitutivos. Theologica Xaveriana, vol. 63/1, núm. 175 (enero-junio): 219-48.

Usarski, Frank. 2013. Etimologia do termo Religião e suas funçãoes didáticas. Diálogo, Revista de ensino religioso, Año XVIII, $\mathrm{n}^{\circ} 71$ (agosto-setiembre): 14-9.

Villela, Marcos y Clebber Gibbon Ratto. 2008. Rastros del fundamentalismo pedagógico. en la formación de profesores. Archivos de Ciencias de la Educación 2(2): 1-14. 